\title{
ukolaclub
}

\section{bar americano}

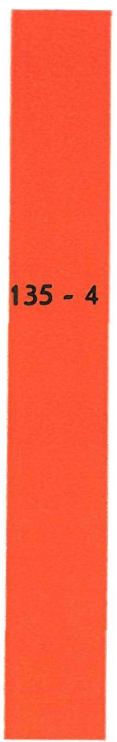

En la calle de Serrano, aprovechando un semisótano dedicado a otro negocio anteriormente, se ha instalado un bar americano, de cuyo interior ofrecemos algunos pormenores. Se han cuidado, especialmente, las condiciones acústicas, resueltas por medio de un techo de escayola perforada, con vitrofib en su parte superior, y paredes de madera, que contribuyen a darle un ambiente cálido y acogedor. El soporte de hierro laminado existente en el centro del local, cuya supresión hubiera sido costosa, se ha revestido con lajas de mármol que le convierten en un elemento decorativo.

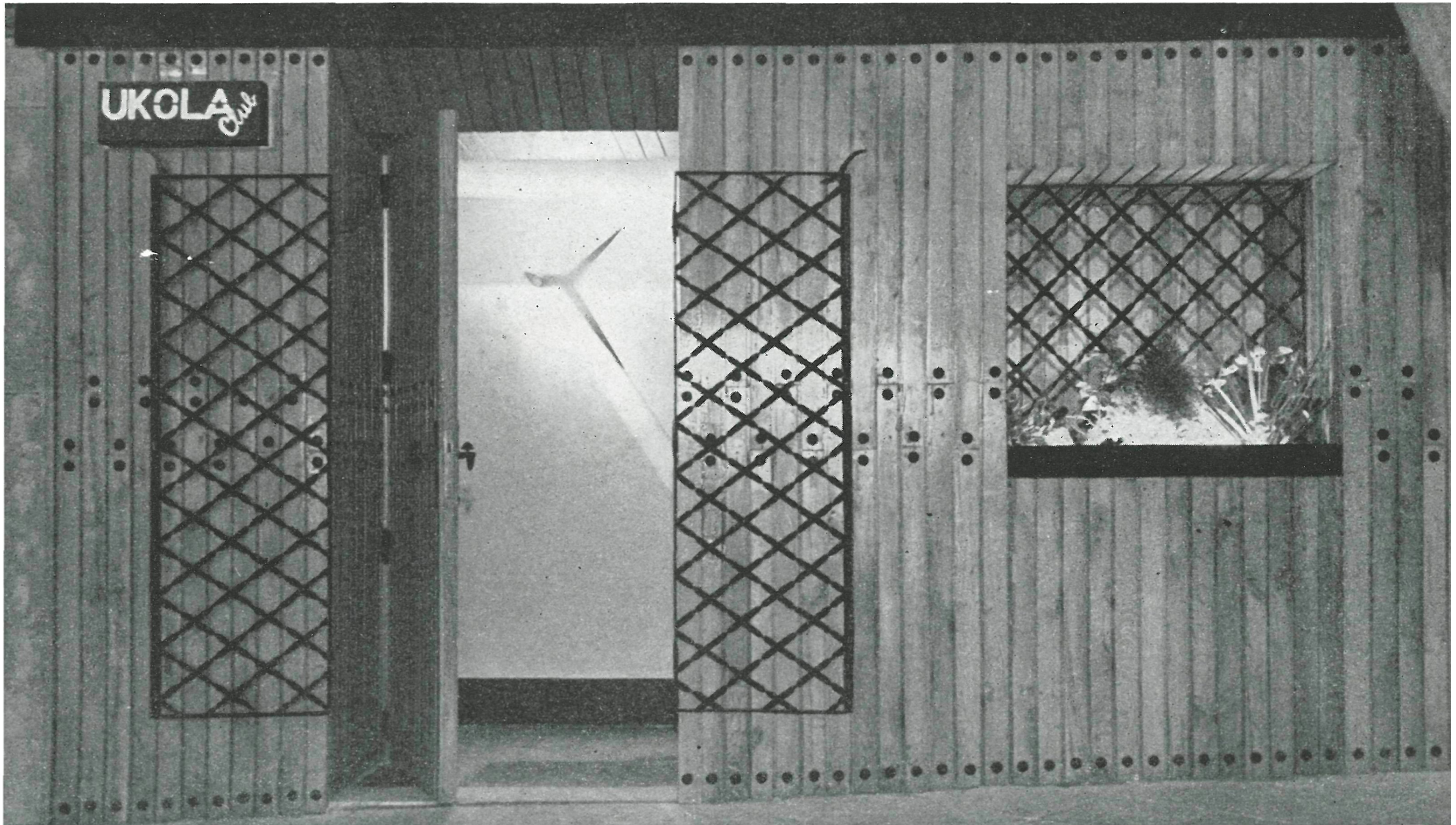

proyecto y decoración

J. R. AZPIAZU, arquitecto

J. L. MARTIN TORDESILLAS, aparejador 


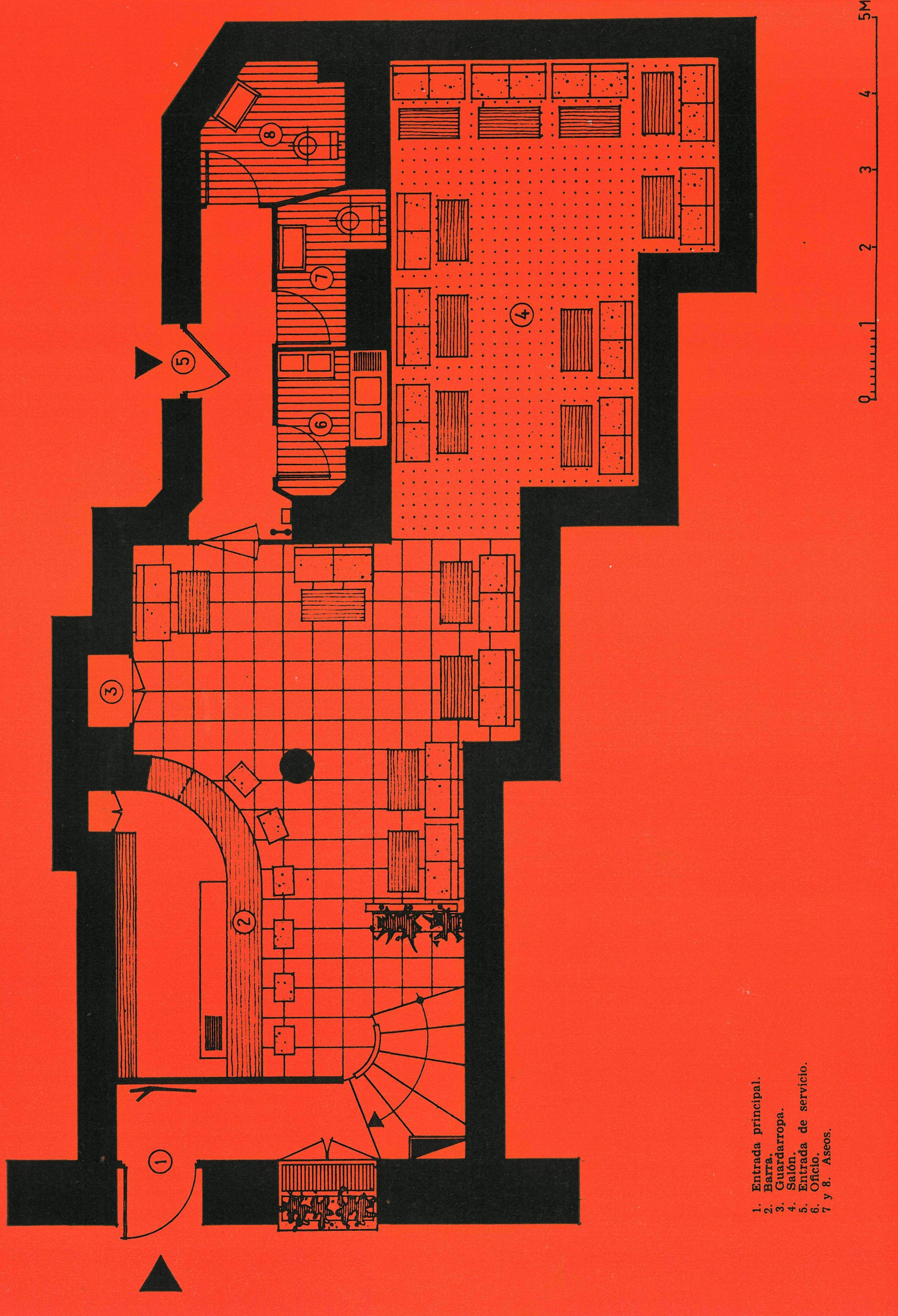



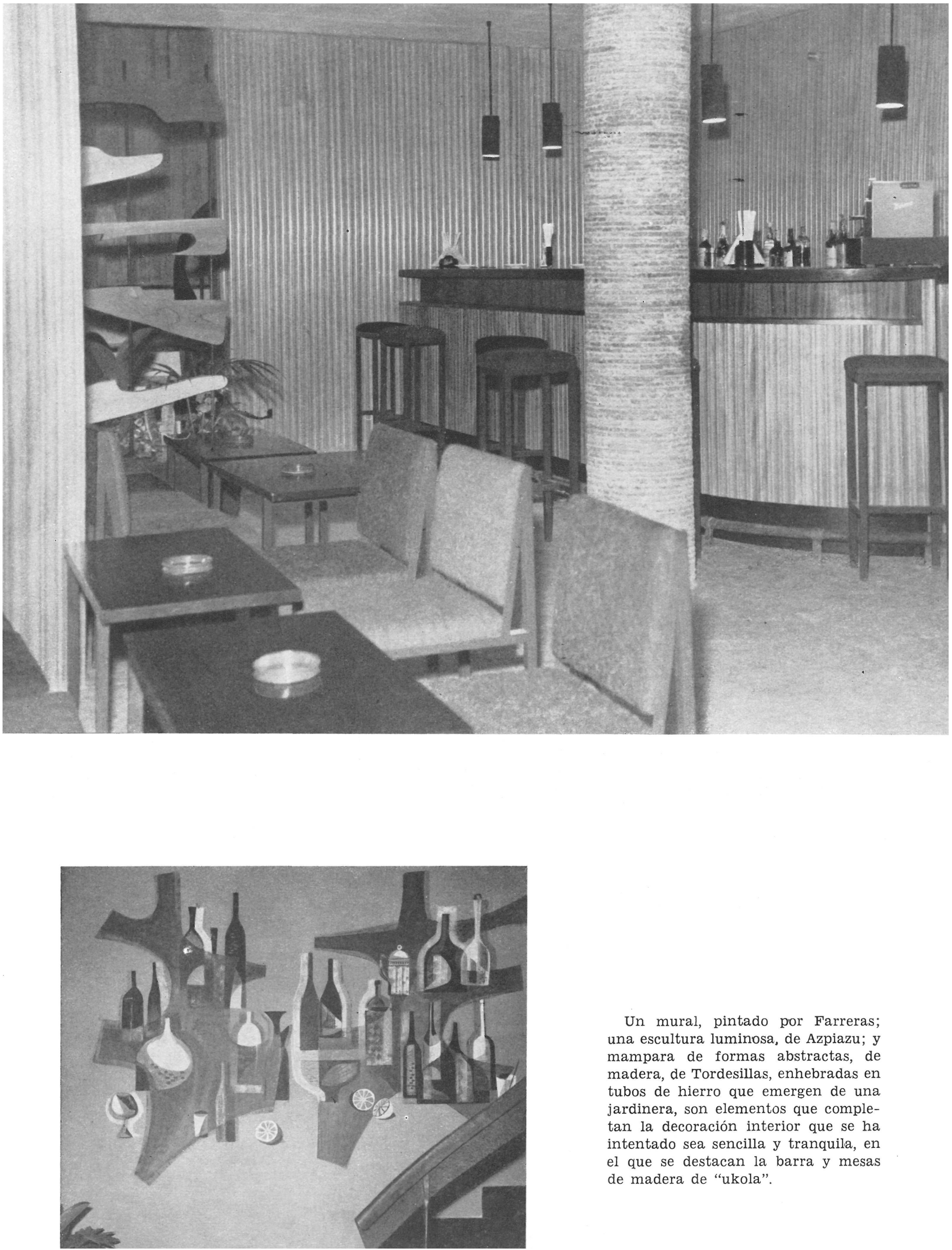

Un mural, pintado por Farreras; una escultura luminosa, de Azpiazu; y mampara de formas abstractas, de madera, de Tordesillas, enhebradas en tubos de hierro que emergen de una jardinera, son elementos que completan la decoración interior que se ha intentado sea sencilla y tranquila, en el que se destacan la barra y mesas de madera de "ukola". 


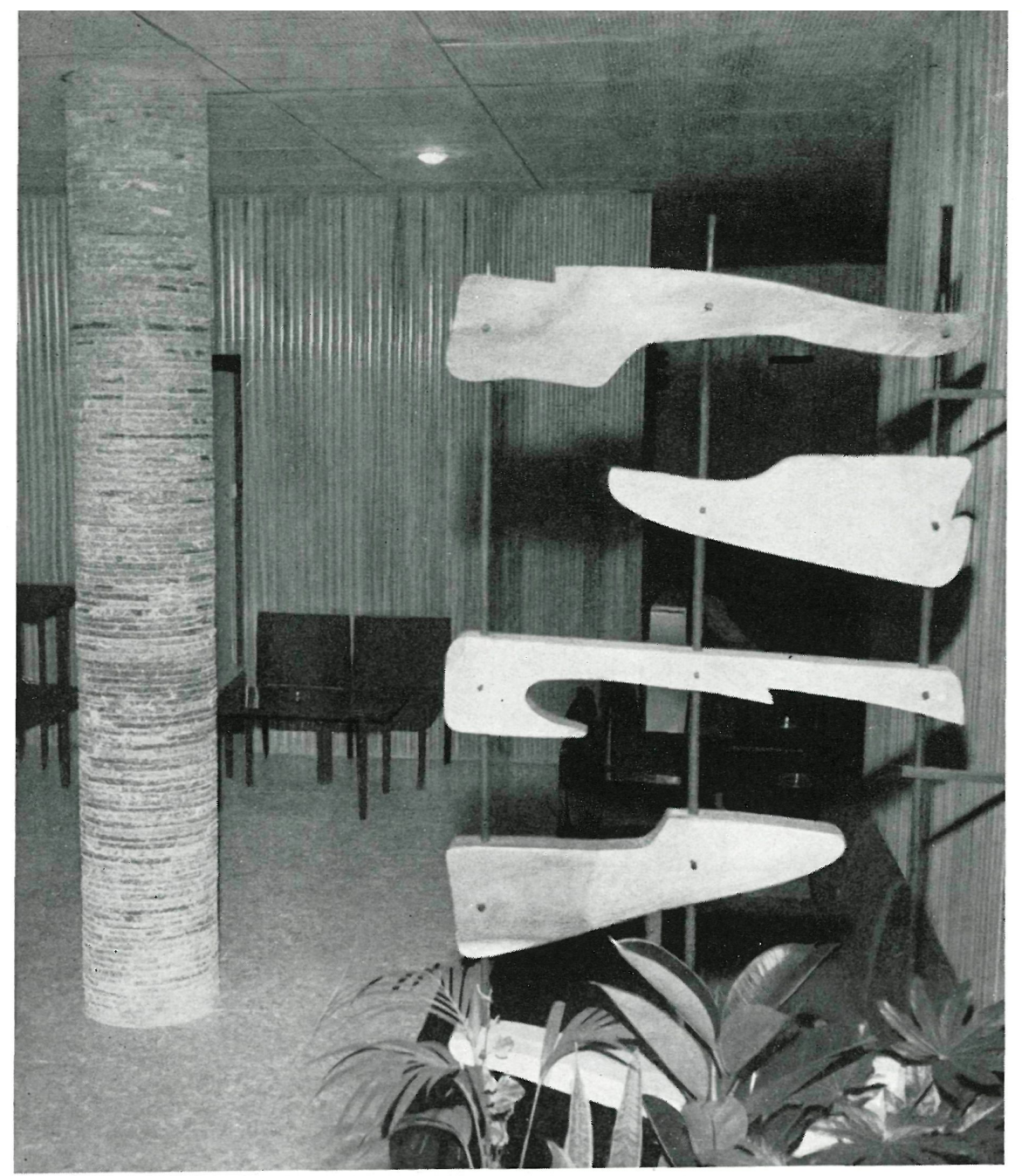

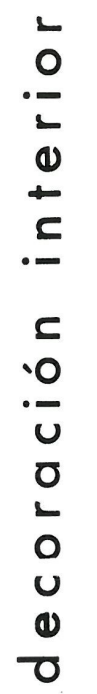
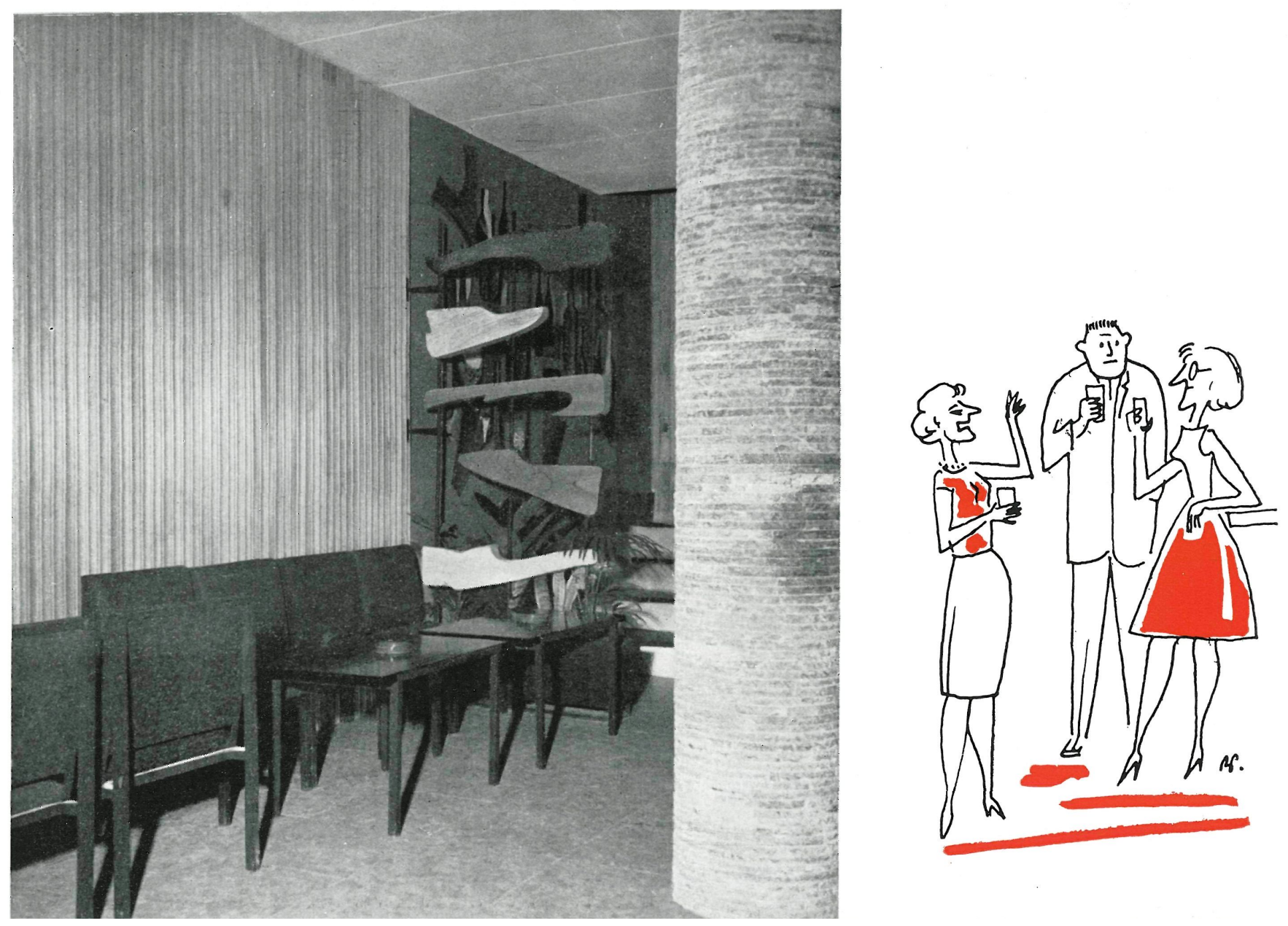


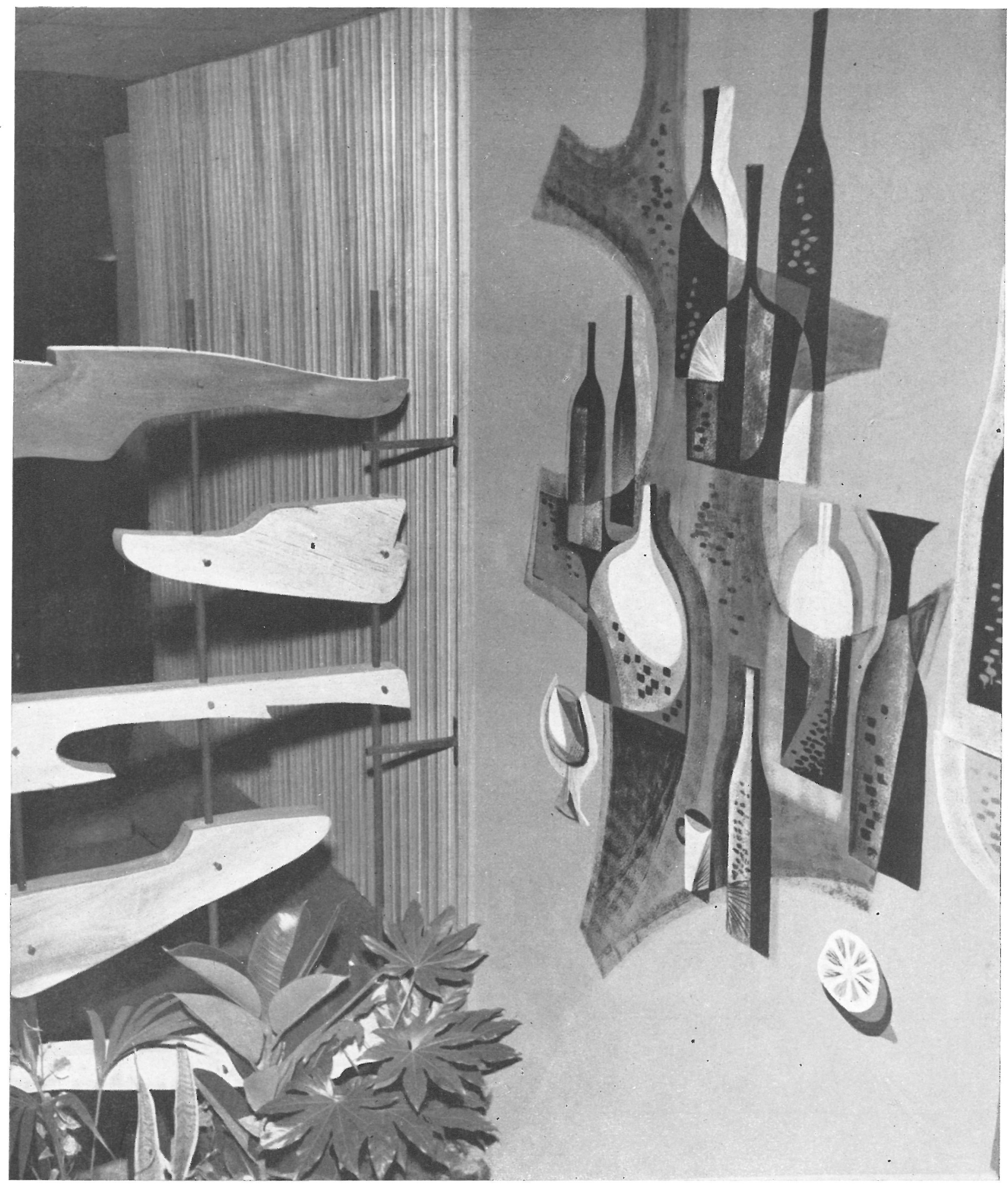

La fachada es de composición muy simple: el enlistonado vertical, de madera de roble; celosías, de hierro forjado, en puerta y ventana, y una jardinera con plantas exóticas, constituyen los elementos de su composición. 